DOI: https://doi.org/10.24127/ajpm.v10i3.3584

\title{
PENGEMBANGAN BAHAN AJAR SPLDV (MASTERING MATH) BERBASIS MOBILE LEARNING UNTUK MENINGKATKAN KEMAMPUAN LITERASI MATEMATIKA SISWA
}

\author{
Sri Susantini ${ }^{1}$, Lilis Chotimah ${ }^{2}$, Ani Nuraini ${ }^{3}$, Poppy Yaniawati ${ }^{4 *}$ \\ 1,2,3,4* Magister Pendidikan Matematika, Universitas Pasundan Bandung, Indonesia \\ *Corresponding author. \\ E-mail : sri.susantini@yahoo.com ${ }^{1)}$ \\ lilischotimah1992@gmail.com $^{2)}$ \\ $\underline{\text { nuraeni_krangkeng@yahoo.com }}^{3)}$ \\ pyaniawati@unpas.ac.id $^{4 *}$
}

Received 24 February 2021; Received in revised from 13 September 2021; Accepted 23 September 2021

\begin{abstract}
Abstrak
Proses pembelajaran matematika dapat dilaksanakan menggunakan suatu konteks yang dirancang pada sebuah bahan ajar berbasis mobile learning dengan memanfaatkan perangkat teknologi seperti smartphone yang sudah terbiasa digunakan siswa, namun pemanfaatannya belum maksimal. Penelitian pengembangan ini bertujuan menghasilkan bahan ajar berbasis mobile learning pada materi SPLDV untuk melihat peningkatan kemampuan literasi matematika siswa. Penelitian ini berpedoman pada langkah-langkah model pengembangan Rowntree. Model pengembangan ini, dikelompokkan pada tiga tahapan pengembangan yaitu tahap perencanaan, tahap pengembangan, dan tahap evaluasi. Pada tahap evaluasi, peneliti menggunakan model evaluasi formatif Tessmer yaitu: (1) self evaluation; (2) expert review ; (3) one-to-one evaluation; (4) small group evaluation; dan (5) field test. Dengan teknik pengumpulan data berupa: pedoman wawancara, angket untuk ahli materi, angket untuk ahli media, angket untuk respon siswa, dan instrumen tes. Subjek penelitian ini adalah siswa kelas VIII di SMPN 23 Kota Bandung. Hasil penelitian ini menunjukan bahwa bahan ajar SPLDV berbasis mobile learning yang dikembangkan, dinilai valid dan layak sebagai salah satu sumber pembelajaran matematika dan efektif dalam meningkatkan kemampuan literasi matematika siswa.
\end{abstract}

Kata kunci : Literasi matematika; mobile learning; SPLDV.

\begin{abstract}
Learning process of mathematics can be carried out using a context that is designed on a mobile learning-based teaching material by utilizing technological devices such as smartphones that are already used by students, but the benefits are not maximized. This development research aims to produce mobile learning based teaching materials on SPLDV material to see the increase in students' mathematical literacy skills. Guided by the steps of the Rowntree development model. This development model is grouped into three stages of development, the stage stage, stage stage, stage stage, and evaluation stage. At the evaluation stage, the researcher used Tessmer's formative evaluation model, namely: (1) self evaluation; (2) expert review; (3) one-to-one evaluation; (4) small group evaluation; and (5) field testing. With data collection techniques in the form of: new interviews, questionnaires for material experts, questionnaires for media experts, questionnaires for student responses, and test instruments. The subjects of this study were students of class VIII at SMPN 23 Bandung. The results showed that the mobile learning-based SPLDV teaching materials developed were valid and feasible as a source of mathematics learning and were effective in improving students' mathematical literacy skills.
\end{abstract}

Keywords: Mathematical literacy; mobile learning; SPLDV.

This is an open access article under the Creative Commons Attribution 4.0 International License 
DOI: https://doi.org/10.24127/ajpm.v10i3.3584

\section{PENDAHULUAN}

Pendidikan matematika yang berkualitas dan bermakna merupakan salah satu cara untuk meningkatkan potensi sumber daya manusia (SDM). Hal itu pula yang merupakan salah satu kunci untuk menyiapkan SDM yang memadai, sehingga mampu menjawab tantangan zaman. Pendidikan Matematika yang berkualitas dapat terlaksana dengan program penilaian yang baik, hal ini sejalan dengan perhatian Programme for International Student Assessment (PISA) yaitu suatu program penilaian dalam bidang membaca, matematika dan sains yang bertujuan untuk mengetahui kemampuan siswa dalam menerapkan ilmu pengetahuan yang sudah meraka pelajari. PISA menggunakan soal-soal yang berbasis dunia nyata sehingga siswa membutuhkan proses matematisasi untuk menyelesaikan permasalahan dunia nyata tersebut secara matematika, karena aktivitas siswa merupakan inti dari proses pembelajaran di masa depan (Yaniawati, 2012). Kemampuan untuk matematisasi suatu fenomena sebagai model secara matematika disebut kemampuan literasi matematika (Pradana, Sholikhah, Maharani, \& Kholid, 2020). Dalam pembelajaran matematika seperti ini, pengembangan kemampuan literasi matematika akan menjadi bagian penting dalam kemampuan pemecahan masalah yang merupakan keterampilan mendasar yang mutlak sangat dibutuhkan di abad ke-21 (Zahid, 2020).

\section{Lembaga Educational Testing}

Service (ETS) mengelompokkan beberapa keterampilan pada abad ke-21 menjadi beberapa kelompok. Kelompok pertama disebut dengan keterampilan pembelajaran dan inovasi, yang meliputi kemampuan berpikir kritis atau problem solving, creativity atau innovation, collaboration, dan communication. Kelompok berikutnya disebut dengan istilah keterampilan literasi digital yang mencakup tentang literasi informasi, literasi media, dan literasi ICT (information communication technology) (Helaluddin \& Fransori, 2019). Pada abad ke-21 terjadi perubahan besar dalam dunia indusri dan disebut sebagai revolusi industri 4.0 juga cukup signifikan dalam dunia pendidikan, reorientasi pendidikan dari pola teacher centered learning menuju student centered learning mau tidak mau memang harus mengikutsertakan aplikasi teknologi yang merupakan produk revolusi industri 4.0 dalam proses pendidikan (Lase, 2019). Pemanfaatan teknologi yang tepat harus dijadikan sebagai salah satu solusi di dunia pendidikan dalam menghadapi revolusi industri 4.0. Pemanfaatan teknologi tersebut, selain sebagai upaya mengatasi permasalahan teknis pembelajaran, juga sebagai upaya untuk menjawab masalah substansial pembelajaran (Yaniawati, 2012).

Salah satu yang dapat diterapkan dalam era teknologi saat ini adalah bahan ajar berbasis mobile learning (Hendrayana \& Wahyudin, 2018). Hal ini sejalan dengan penelitian (Sastrawati \& Novallyan, 2017) yang berjudul Pengembangan Media Pembelajaran Interaktif Berbasis Android untuk Pemahaman Konsep Trigonometri. Hasil penelitian ini diperoleh kelayakan masuk pada kriteria baik, sehingga penelitian dan pengembangan ini menarik digunakan sebagai alat penunjang kegiatan pembelajaran baik untuk pendidik maupun peserta didik. Penelitian tersebut juga untuk mengembangkan bahan ajar berbantuan m-learning. Sehingga, penelitian ini bertujuan melakukan pengembangan 
DOI: https://doi.org/10.24127/ajpm.v10i3.3584

bahan ajar berbasis mobile learning pada materi SPLDV untuk meningkatkan literasi matematika siswa.

\section{METODE PENELITIAN}

Penelitian ini merupakan penelitian pengembangan, yaitu penelitian yang bertujuan menghasilkan bahan ajar SPLDV berbasis mobile learning dengan model pengembangan Rowntree. Model pengembangan ini terdiri dari tiga tahap yaitu perencanaan, pengembangan dan evaluasi. Kajian dilakukan dengan menggunakan pendekatan eksperimental terhadap penngunaan bahan ajar SPLDV berbasis mobile learning dalam KBM pada kelas VIII di SMPN 23 Kota Bandung. Perlakuan eksperimen diberikan terhadap dua kelompok atau kelas yang homogen dengan pemanfaatan bahan ajar yang berbeda. Kelompok pertama disebut kelompok eksperimen, yaitu kelompok yang menggunakan bahan ajar SPLDV berbasis mobile learning; kelompok dua disebut kelompok kontrol, yaitu kelompok yang menggunakan baha ajar sebagaimana biasanya. Kedua kelompok tersebut disajikan dengan desain Non Equivalent Control-Grup Pretest-Posttest Design seperti yang disajikan pada Tabel 1 .

Tabel 1. Desain non-equivalent controlgroup pretest-posttest design

\begin{tabular}{cccc}
\hline Kelompok & Pre-test & Perlakukan & Post-test \\
\hline A & O & X & O \\
B & O & - & O
\end{tabular}

Keterangan:
A, B : kelas sampel yang dipilih secara acak
$\mathrm{O} \quad$ : pre-test, post-test
$\mathrm{X}$ : pembelajaran menggunakan bahan ajar SPLDV berbasis m-learning

Populasi dalam penelitian ini adalah seluruh siswa kelas VIII di SMPN 23 Kota Bandung. Penetapan sampel kedua kelompok tersebut dilakukan dengan teknik random sampling. Hal ini dilakukan karena setiap kelompok memiliki peluang yang relatif sama. Selain itu, SMPN 23 Kota Bandung dipilih karena lokasinya dekat, sehingga memudahkan mobilitas dalam melakukan kajian.

Teknik pengumpulan data yang digunakan pada penelitian ini yaitu tes dan wawancara. Instrumen tes literasi matematika materi SPLDV dalam konten PISA, soal terdiri dari 6 butir soal yang telah diujicobakan kepada kelas yang lebih tinggi untuk melihat validitas, reliabilitas, daya pembeda, dan tingkat kesukaran. Setelah diujicobakan soal dirancang pada perangkat mobile learning yang divalidasi oleh ahli untuk mengetahui kevalidan dan kelayakan produknya. Kemudian dilanjutkan dengan menguji cobakan produk kepada 4 siswa pada tahap one-to one evaluastion 6 siswa pada tahap small group, dan 30 siswa pada tahap filed test, agar program yang dikembangkan valid dan layak digunakan sebagai media pembelajaran yang baik dalam meningkatkan literasi matematika. Sedangkan wawancara dilakukan terhadap subjek setelah dilaksanakan tes.

Teknik analisis data yang digunakan dalam penelitian ini adalah Q-Cochran untuk mengetahui apakah ada perbedaan antara lebih dua sampel yang berhubungan. Salah satu syarat dalam melakukan uji ini, data hanya mempunyai 2 nilai saja, yaitu baik atau buruk. Uji Cochran Q, uji ini juga digunakan untuk mengetahui atribut produk apa saja yang dianggap sah/valid. Kemudian dalam menetukan atribut yang valid didasarkan pada 
metode Cochran $\mathrm{Q}$ Test yaitu dengan membandingkan antara $\mathrm{Q}_{\text {hitung }}$ dan $\mathrm{Q}_{\text {tabel. }}$ Penentuan $\mathrm{Q}_{\text {tabel }}$ diperoleh dari tabel $C h i$ Square dengan derajat kebebasan atribut $(\mathrm{db})=\mathrm{K}-1$ dengan tingkat kesalahan ( $\alpha$ ) 5\% sedangkan $\mathrm{Q}_{\text {hitung }}$ diperoleh dari rumus:

$$
Q=\frac{(k-1)\left[k \Sigma_{j=1}^{k} G_{j}{ }^{2}-\left(\Sigma_{j=1}^{k} G_{j}\right)^{2}\right]}{k \Sigma_{i=1}^{N} L_{i}-\Sigma_{i=1}^{N} L_{i}^{2}}
$$

Hipotesis yang akan di uji

$$
\begin{aligned}
H_{o}= & \begin{array}{l}
\text { Kelima validator memberikan } \\
\text { penilaian yang sama. }
\end{array} \\
H_{1}= & \begin{array}{l}
\text { Kelima validator memberikan } \\
\text { penilaian yang tidak sama. }
\end{array}
\end{aligned}
$$

Syarat $H_{o}$ diterima atau tidak berdasarkan nilai probabilitas sebagai berikut : 1) $H_{o}$ diterima , jika probabilitas > 0.05 ; 2) $H_{o}$ ditolak, jika probabilitas $<0.05$. Jika $H_{o}$ diterima berarti proporsi jawaban ya pada semua atribut dianggap sama. Dengan demikian, semua responden dianggap sepakat mengenai semua atribut yang diperhitungkan.. Skor hasil angket yang diperoleh dari respon siswa berupa data kuantitatif diubah dalam bentuk kategori dengan pedoman. Skor ratarata kuantitaif diperoleh dengan menggunakan rumus berikut:

$$
M=\frac{\Sigma X}{N}
$$

Adapun klasifikasi kategori dijabarkan dalam Tabel 1.

Tabel 1. Kriteria penilaian

\begin{tabular}{cc}
\hline Rentang Skor & Kriteria \\
\hline $\boldsymbol{X} \geq \boldsymbol{M}+\boldsymbol{S B i}$ & Sangat layak \\
$\boldsymbol{M}+\boldsymbol{S B} \boldsymbol{B}>\boldsymbol{X} \geq \boldsymbol{M}$ & Layak \\
$\boldsymbol{M}>\boldsymbol{X} \geq \boldsymbol{M}-\mathbf{1 S B i}$ & Kurang layak \\
$\boldsymbol{X}<\boldsymbol{m}-\mathbf{1 S B i}$ & Sangat kurang layak \\
\hline
\end{tabular}

Perhitungan effect size bertujuan untuk mengetahui efektifitas bahan ajar mobile learning terhadap peningkatan kemampuan literasi matematika. Perhitungan tersebut diperoleh dari nilai pretes dan postes.

Effect size $=\frac{\text { PoTAS-PrTAS }}{\text { standard derivation }}$

PoTAS : Posttest Average Score

PrTAS : Pretest Average Score

Adapun klasifikasi dari masingmasing kategori dijabarkan dalam Tabel 2.

Tabel 2. Klasifikasi effect size

\begin{tabular}{cc}
\hline Size & Kriteria \\
\hline $0-0,20$ & Lemah \\
$0,21-0,50$ & Sederhana \\
$0,50-1,00$ & Moderat \\
$>1,00$ & Kuat \\
\hline
\end{tabular}

Sedangkan untuk melihat besarnya peningkatan kemampuan literasi matematika, analisis menggunakan uji $N$-gain, sebagai berikut:

$N-$ gain $=\frac{\text { posttest }- \text { pretest }}{\text { nilai maximum-pretest }} \ldots$

Adapun katagori dari indeks gain adalah sesuai seperti pada Tabel 3 .

Tabel 3. Kategorisasi indeks gain

\begin{tabular}{cc}
\hline Size & Kriteria \\
\hline $\mathbf{G}>\mathbf{0 , 7}$ & Tinggi \\
$\mathbf{0 , 3}<\mathbf{g} \leq \mathbf{0 , 7}$ & Sedang \\
$\mathbf{g} \leq \mathbf{0 , 7}$ & Rendah \\
\hline
\end{tabular}

\section{HASIL DAN PEMBAHASAN}

Tahap perencanaan merupakan tahap awal dalam mekanisme pengelolaan komunikasi atau informasi. Pada tahap perencanaan diawali dengan melakukan diskusi melalui wawancara 
DOI: https://doi.org/10.24127/ajpm.v10i3.3584

yang dilakukan dengan guru matematika sekaligus wakil kepala sekolah bagian kurikulum, yang dilaksanakan pada tanggal 15 Oktober 2019. Hasil wawancara ini menguraikan keadaan siswa dan media belajar yang biasa digunakan pada proses pembelajaran di kelas. Narasumber/guru menjelaskan bahwa sebagian besar siswa merasa kesulitan dalam memahami konsep matematika yang diajarkan, karena buku teks yang biasa digunakan terlalu padat dengan materi dan tidak menarik perhatian siswa. Hal ini membuat kemampuan literasi matematika siswa tidak dapat terolah dengan baik. Kemampuan literasi matematik dapat didefinisikan sebagai kemampuan seseorang untuk merumuskan, menggunakan, menginterpretasikan matematika dalam berbagai konteks pemecahan masalah kehidupan sehari-hari secara efektif. Bahan ajar literasi matematika yang dikembangkan dapat digunakan oleh guru sebagai materi tambahan untuk meningkatkan kemampuan berpikir matematika tingkat tinggi peserta didik (Khikmiyah \& D, 2019). Padahal, pengembangan kontekstual yang dianggap dapat memberikan pembelajaran yang bermakna bagi siswa, di desain khusus pada perangkat mobile yang dilengkapi dengan gambar, animasi dan fitur-fitur pendukung yang dapat menarik dan memberikan kemudahan untuk siswa dalam mempelajari konsep matematika. Pembelajaran dengan bantuan media tekonologi (mobile learning) ini memiliki peran yang cukup besar dalam meningkatkan motivasi siswa karena belajar menjadi mudah dan cepat (Hendri, Hudiono, \& Suratman, 2015). Hal ini sejalan dengan penelitian (Abida \& Kusuma, 2019), bahwa pembelajaran dengan memanfaatkan media mobile learning, sangatlah penting dalam pembelajaran matematika di zaman revolusi industri 4.0. Menurut Freudethal bahwa suatu ilmu pengetahuan akan bermakna bagi pembelajar jika proses belajar melibatkan masalah realistik atau menurut CORD suatu pengetahuan akan menjadi bermakna bagi siswa jika proses pembelajan dilaksanakan dalam suatu konteks dilaksanakan dalam suatu konteks (Abdurahim, 2016).

Pengembangan ini meliputi pengembangan konten yang terdapat dalam bahan ajar mobile learning yang terdiri dari teks, gambar, animasi, latihan soal, materi, peta konsep, posttest agar mudah dibaca di smartphone atau bentuk digital. Konten bahan ajar mobile learning meliputi KD, peta konsep, sejarah SPLDV, materi SPLDV (didahului dengan menyajikan masalah kontekstual dalam kehidupan sehari-hari), bentuk SPLDV, cara penyelesaian SPLDV (metode eliminasi, subtitusi, dan grafik), rangkuman, referensi, posttest, latihan soal, dan kuis. Adapun peta konsep untuk merancang aplikasi berbentuk mobile learning dapat dilihat pada Gambar 2.

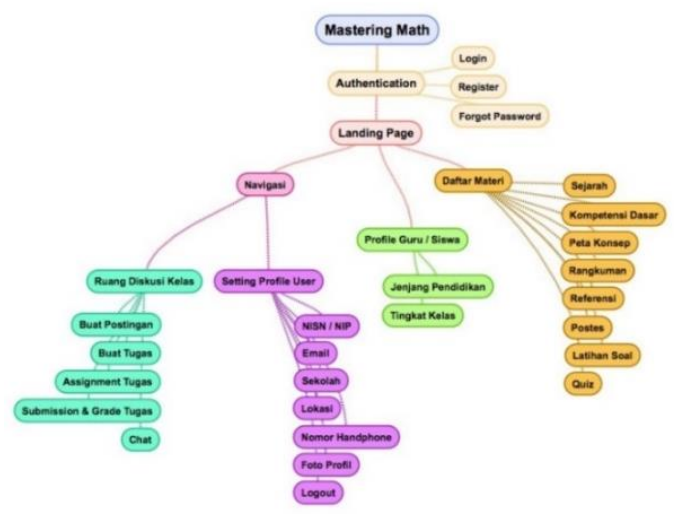

Gambar 2. Peta konsep perancangan mastering math

Hasil pada tahap produksi protoype, draft yang telah disusun kemudian dibuat menjadi produk yang 
DOI: $\underline{\text { https://doi.org/10.24127/ajpm.v10i3.3584 }}$

disebut prototype. Dalam penelitian ini adalah sebuah Mastering Maths yang berbasis mobile learning dan dapat diakses secara online pada smartphone android. Kemudian di desain dengan melakukan proses koding pada studio kode ineterface menggunakan bahasa pemprograman javasript. Adapun hasil dari proses koding pada studio kode interface dengan menggunakan bahasa pemrograman berupa javascript dapat dilihat pada Gambar 3.
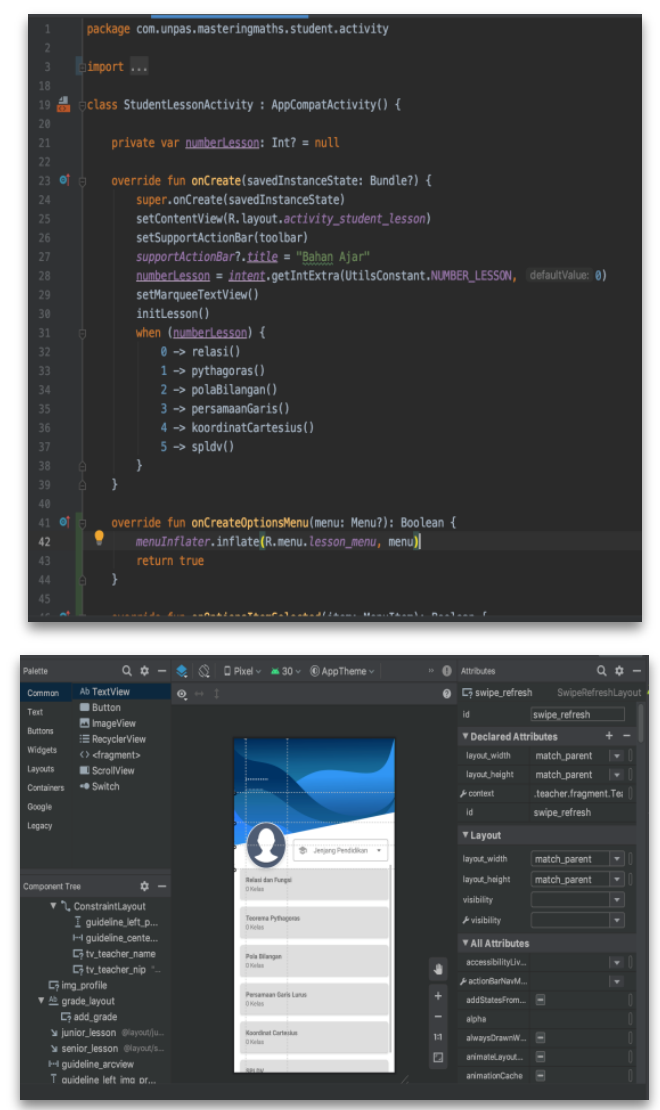

Gambar 3. Tampilan proses coding mastering maths

Menurut (Annisa, 2020), bentuk perangkat bahan ajar mobile learning yang dikembangkan menggunakan aplikasi mastering math layak untuk digunakan. Proses coding berbasis text ini akan menampilkan sebuah aplikasi berbasi grafis yang mudah digunakan oleh user, berikut tampilan bahan ajar mastering maths berbasis mobile learning yang telah melalui proses coding. Tampilan utama dari mastering math dapat dilihat pada Gambar 4 .
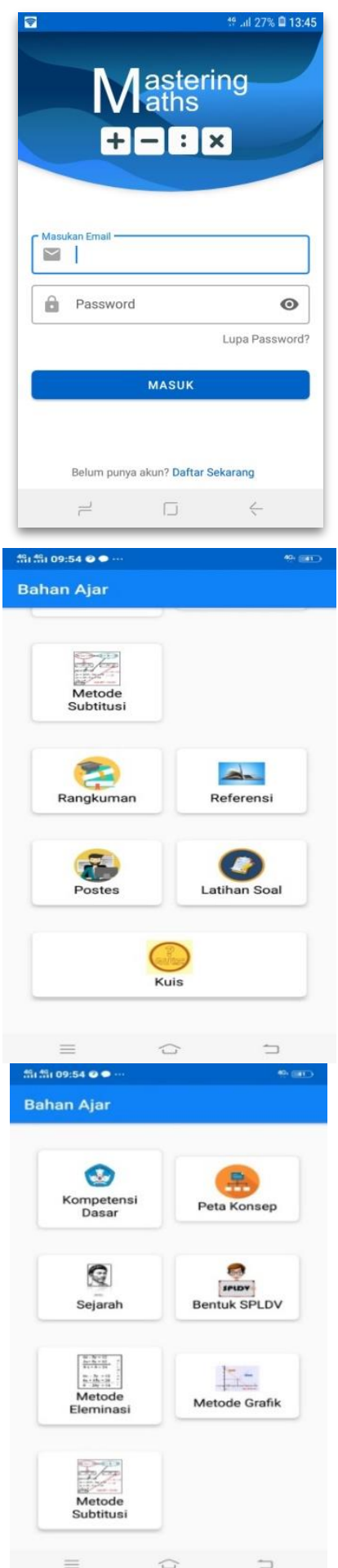

Gambar 4. Tampilan utama mastering maths 
DOI: https://doi.org/10.24127/ajpm.v10i3.3584

Prototype yang dihasilkan kemudian divalidasi oleh 5 orang ahli, yang terdiri dari 2 orang guru besar pendidikan matematika, 1 orang ahli matematika sekaligus guru matematika dan 2 orang programmer. Penilaian tersebut kemudian dianalisis menggunakan $Q$-Cochran. Uji Cochran $\mathrm{Q}$ digunakan untuk mengetahui atribut produk apa saja yang dianggap sah/valid dan digunakan untuk mengetahui apakah ada perbedaan antara lebih dua sampel yang berhubungan. Salah satu syarat dalam melakukan uji ini, data hanya mempunyai 2 nilai saja, yaitu baik atau buruk.

Tabel 4. Hasil uji q-cochran

\begin{tabular}{cccc}
\hline $\mathbf{N}$ & Cochran's Q & Df & Asymp. Sig. \\
\hline 5 & $49,712^{\text {a }}$ & 38 &, 097 \\
\hline
\end{tabular}

Hasil uji Q-Cochran dengan bantuan SPSS disajikan pada Tabel 4. Dari hasil pada Tabel 4, pada Asymp Sig terlihat bahwa nilai probabilitas 0.000. Maka $H_{o}$ diterima $(0.097>0.05)$. Dengan demikian keputusan yang diambil adalah Kelima validator memberikan penilaian yang sama. komentar dan saran yag diberikan validator kemudian menjadi rujukan untuk melakukan revisi pembuatan prototype selanjutnya, dan dapat dilanjutkan untuk melakukan uji coba produk. Selain memberikan penilaian berdasarkan kriteria yang telah ditetapkan, diminta pula komentar dan kritik kepada validator sebagai bahan masukan revisi untuk produk pada tahap selanjutnya. Adapun komentar dan kritik yang diberikan oleh validator dapat dilihat pada Tabel 5 .

Tabel 5. Komentar validator

\begin{tabular}{|c|c|c|}
\hline No & Aspek Validasi & Komentar \\
\hline 1 & Tampilan (Media) & $\begin{array}{l}\text { Secara keseluruhan, dari awal membuka/kembali, tombol } \\
\text { navigasi pergerakan slide cukup baik, mudah dipahami } \\
\text { alurnya. Kekurangannya minor, ada beberapa gambar yang } \\
\text { masih kecil tapi mungkin tidak masalah jika dibuka dengan } \\
\text { tablet atau tampilan layar lebar. }\end{array}$ \\
\hline 2 & Program & $\begin{array}{l}\text { Untuk mengakses kuis, guru harus memberikan kode } \\
\text { aksesnya agar soal tetap terjaga sebelum pelaksanaan tes } \\
\text { berlangsung } \\
\text { Kode guru untuk invite atau mengundang siswa ke dalam } \\
\text { kelas harus lebih simpel (atau guru dapat membuatnya } \\
\text { sendiri) }\end{array}$ \\
\hline 3 & Pembelajaran & $\begin{array}{l}\text { Quiz dapat diakses oleh siswa lebih dari satu kali agar siswa } \\
\text { dapat melatih dan memperbaiki pemahamannya. }\end{array}$ \\
\hline
\end{tabular}

Tahap ini bertujuan untuk melihat seberapa besar kelayakan produk untuk digunakan sebagai salah satu bahan ajar SPLDV berbasis mobile learning. Uji coba produk dilakukan sebanyak 3 tahap, yaitu: (1) one-to-one evaluation yang diuji cobakan pada 4 orang siswa kelas 9 yang telah menerima materi SPLDV, selanjutnya melakukan revisi prototype 2; (2) small group, uji coba tahap ke-2 melibatkan 6 orang siswa kelas 9, dan melakukan revisi pada prototype akhir; (3) field test uji coba produk tahap akhir yang melibatkan 30 orang siswa kelas VIII (kelas eksperimen). Hasil dari tahapan uji coba yang dilakukan disajikan pada Tabel 6. 
DOI: https://doi.org/10.24127/ajpm.v10i3.3584

Tabel 6. Aspek kelayakan bahan ajar SPLDV berbasis mobile learning

\begin{tabular}{lccc}
\hline \multicolumn{1}{c}{ Aspek } & One-to-one Evaluation & Small Group & Field Test \\
\hline Pembelajaran & 2,83 & 3,21 & 3,54 \\
Tampilan & 2,87 & 3,53 & 3,64 \\
Pemrograman & 2,72 & 3,17 & 3,40 \\
Jumlah Keseluruhan & 8,43 & 9,90 & 10,57 \\
Rerata Skor Keseluruhan & 2,81 & 3,30 & 3,52 \\
Kategori & Layak & Sangat Layak & Sangat Layak \\
\hline
\end{tabular}

Berdasarka hasil uji coba produk yang telah dilakukan, maka pengembangan bahan ajar SPLDV berbasis mobile learning dinyatakan valid dan layak digunakan sebagai alternatif media pembelajaran pada proses kegiatan belajar mengajar di kelas. Hal ini sejalan dengan penelitian (Hardiansyah, Rusmono, \& Winarsih, 2018) yang menujukkan bahwa bahan pembelajaran berbasis android atau dikenal dengan mobile learning cukup mudah untuk dipraktikan di kelas maupun di rumah karena praktis dan efektif dengan menyajikan tampilan yang menarik untuk peserta didik. Sejalan juga dengan penelitian (Hardiansyah et al., 2018), bahwa bahan ajar berbasis mobile learning ini pun sangat efektiv digunakan oleh peserta didik, karena sebagian besart telah akrab dengan aplikasi smartphone. Begitu pula dengan (Handayani, 2014), bahan ajar dalam bentuk mobile learning sangat membantu mahasiswa dalam belajar, hal ini dikarenakan kemudahan akses dan praktis.

Peningkatan kemampuan literasi matematika siswa pada kelompok yang menggunakan bahan ajar SPLDV berbasis mobile learning lebih baik, hal dibuktikan dengan adanya perbedaan peningkatan yang signifikan dengan kemampuan literasi matematika siswa di kelompok yang menggunakan bahan ajar SPLDV berbasis mobile learning sebesar 0,681 dan 0,516 pada peningkatan kelompok siswa yang menggunakan buku teks. Sehubung dengan fakta tersebut, maka kemampuan literasi matematika siswa pada seluruh kelompok perlu menjadi perhatian. Analisis juga dilakukan pada perbedaan uraian jawaban siswa unggul dan asor. Kelompok siswa unggul secara parsial lebih baik dibandingkan dengan kelompok siswa asor. Kelompok siswa unggul dapat memberikan jawaban dengan sistematika yang logis, varian jawaban yang luas dan menyeluruh dengan melakukan sedikit kesalahan. Sedangakan kelompok siswa asor memberikan jawaban dengan uraian yang relatif acak dengan varian yang hampir sama dengan siswa lain, dan lebih banyak melakukan kesalahan. Fakta tersebut menunjukan bahwa bahan ajar SPLDV berbasis mobile learning yang didesain dengan pendekatan kontekstual dapat membantu siswa dalam menumbuh kembangankan proses berpikir secara matematika. Hal ini sejalan dengan kesimpulan dari beberapa penelitian yang menyatakan bahwa penggunaan aplikasi android dalam pembelajaran dapat meningkatkan pemahaman konsep siswa ((Astuti, Dasmo, \& Sumarni, 2018); (Sastrawati \& Novallyan, 2017); dan (Lestari, Senjaya, \& Ismunandar, 2014). Adapun hasil dari analisis terhadap perbedaan jawaban siswa unggul dan asor dapat dilihat pada Gambar 5. 


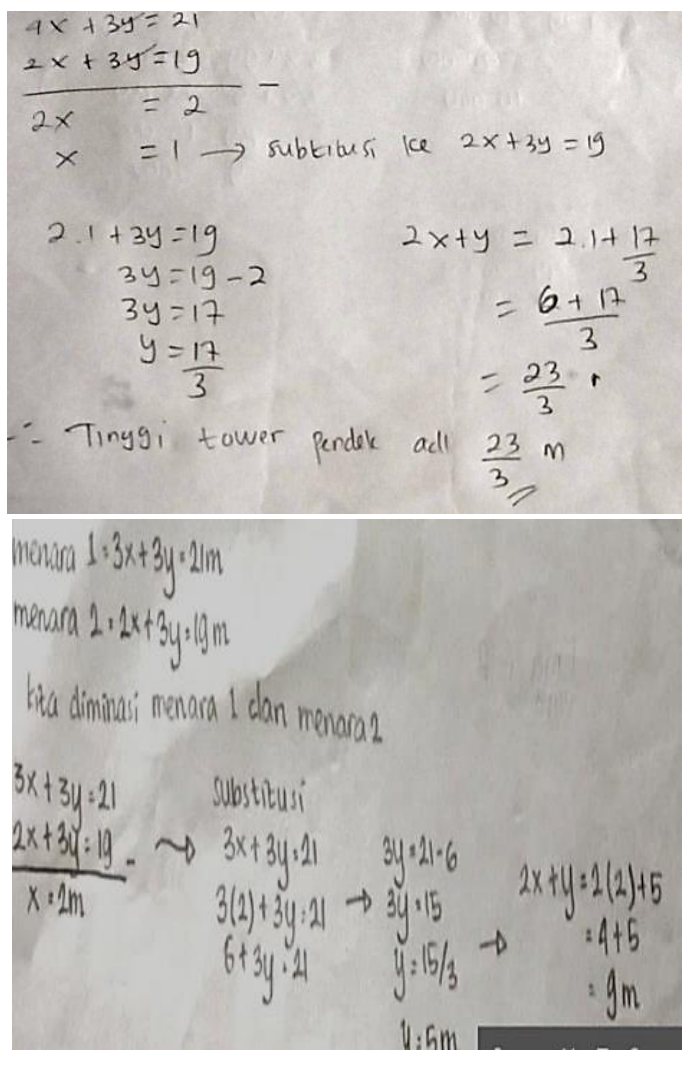

Gambar 5. Analisis perbedaan jawaban siswa unggul dan asor pada soal literasi matematika

Hasil jawaban siswa unggul, menunjukan sebagian besar siswa memahami konsep SPLDV yakni memahami fungsi koefesien dan variabelnya dan metode penyelesaian SPLDV yaitu dengan metode eliminasi dan subtitusi. Selain itu siswa kelas unggul memberikan kesimpulan hasil akhir sebagai informasi. Hanya saja siswa sedikit melakuan kesalahan karena tidak melakukan pemisalan terlebih dahulu. Sedangakan jawaban yang dilberikan siswa ashor pada soal literasi matematika, Kesalahan yang sangat terlihat yaitu memberikan satuan meter pada persamaan dan tidak memberikan pemisalan terlebih dahulu, sehingga nilai konstanta seperti bernilai nol. Banyak siswa juga tidak menyimpulkan hasil pekerjaan, padahal simpulan perhitungan amatlah penting sebagai informasi akhir. Sehingga dapat disimpulkan bahwa kesalahan lebih banyak dilakukan pada siswa asor dibandingkan dengan siswa unggul. Selain itu, utuk melihat efektivitas pengembangan bahan ajar SPLDV berbasis mobile learning analisia menggunakan calculator effect size, dan dapat diakses pada website berikut https://www.uccs.edu/lbecker/.

Perhitungan effect size bertujuan untuk mengetahui efektifitas bahan ajar mobile learning terhadap peningkatan kemampuan literasi matematika. Perhitungan tersebut diperoleh dari nilai pretes dan postes. Perhitungan efek size dapat dilihat pada Tabel 7 .

Tabel 7. Perhitungan Effect Size

\begin{tabular}{ccccc}
\hline \multicolumn{2}{c}{ Mean } & Standar & Effect & Kategori \\
\cline { 1 - 4 } Pretest & Postest & Deviasi & Size & Kat \\
\hline 23,8750 & 75,6563 & 6,58056 & 1,93 & Kuat \\
\hline
\end{tabular}

Tabel 7 menunjukan bahwa nilai perhitungan effect size adalah 1,93 yang termasuk pada kategori "kuat". Maka, dapat disimpulkan bahwasannya pengembangan bahan ajar spldv berbasis mobile learning cukup efektif untuk meningkatkan kemampun literasi matematika siswa.

\section{KESIMPULAN DAN SARAN}

Penelitian ini menghasilkan produk berupa bahan ajar SPLDV berbasis mobile learning. Hasil uji coba yang dilakukan secara keseluruhan dapat disimpulkan bahwa bahan ajar SPLDV berbasis mobile learning dikatakan valid dan layak, serta efektif untuk meningkatkan kemampuan literasi matematika siswa. Adapun saran untuk penelitian ini adalah hal yang menjadi objek dari penelitiannya tidak hanya berbatas pada literasi saja, namun masih bisa dikembangkan dengan objek yang lain yang lebih beragam. 
DOI: $\underline{\text { https://doi.org/10.24127/ajpm.v10i3.3584 }}$

\section{DAFTAR PUSTAKA}

Abdurahim, A. (2016). Keefektifan Model Pembelajaran Resik Ditinjau dari Sikap, Motivasi, dan Kemampuan Berpikir Kritis Matematis Siswa SMP. Jurnal Riset Pendidikan Matematika, 3(2), 137149.

Abida, R., \& Kusuma, A. B. (2019). Pemanfaatan Mobile Learning Pada Pelajaran Matematika di Revolusi Industri 4.0. Prosiding SENDIKA, 5(1), 229-235.

Annisa, D. (2020). Pengembangan Bahan Ajar Mobile Learning pada Materi Koordinat Kartesius untuk Meningkatkan Kemampuan Representasi Matematis dan Motivasi Belajar Siswa SMP. Universitas Pasundan.

Astuti, I. A. D., Dasmo, \& Sumarni, R. A. (2018). Pengembangan Media Pembelajaran Berbasis Android dengan Menggunakan Aplikasi Appypie di SMK Bina Mandiri Depok. JPKM (Jurnal Pengabdian Kepada Masyarakat), 24(2), 695701.

Handayani, R. D. (2014). Pengembangan Bahan Ajar Elektronik Berbasis Mobile-Learning pada Mata Kuliah Optik di FKIP Universitas Jember. Ta'dib, 17(1), 81-85.

Hardiansyah, H., Rusmono, \& Winarsih, M. (2018). PENGEMBANGAN BAHAN AJAR BERBASIS MOBILE LEARNING. Prosiding Seminar Dan Diskusi Nasional Pendidikan Dasar, 327-331. Jakarta: Universitas Negeri Jakarta.

Helaluddin, \& Fransori, A. (2019). INTEGRASI THE FOUR CS DALAM PEMBELAJARAN BAHASA DI ERA REVOLUSI INDUSTRI 4.0. EduHumaniora: Jurnal Pendidikan Dasar, 11(2), 95106.

Hendrayana, A., \& Wahyudin. (2018). Mobile Learning to Improve Mathematics Teachers Mathematical
Competencies. Journal Physics. Conf. Series.

Hendri, M., Hudiono, B., \& Suratman, D. (2015). Pemanfaatan Mathematics Mobile Learning Application Smartphone OS.Android Untuk Meningkatkan Efektivitas Belajar SPLDV di SMP. Jurnal Pendidikan Dan Pembelajaran Khatulistiwa, 4(5), 1-11.

Khikmiyah, F., \& D, P. A. R. (2019). Mathematics Literasy Mobile Learning Application: Pengembangan Bahan Ajar Berbasis Android. DIDAKTIKA, 25(2), 128139.

Lase, D. (2019). Pendidikan di Era Revolusi Industri 4.0. Jurnal Sundermann (JCETS), 1(1), 28-43.

Lestari, A. I., Senjaya, A. J., \& Ismunandar, D. (2014). Pengembangan Media Pembelajaran Berbasis Android Menggunakan Appy Pie Untuk Melatih. Pedagogy, 4(2), 1-9.

Pradana, L. N., Sholikhah, O. H., Maharani, S., \& Kholid, M. N. (2020). Virtual Mathematics Kits (VMK): Connecting Digital Media to Mathematical Literacy. IJET, 15(3), 234-241. https://doi.org/10.3991/ijet.v15i03.1 1674

Sastrawati, E., \& Novallyan, D. (2017). Pengembangan Media Pembelajaran Interaktif Berbasis Android Untuk Pemahaman Konsep Trigonometri. IJER, 2(2), 72-76.

Yaniawati, R. P. (2012). Pengaruh ELearning untuk Meningkatkan Daya Matematik Mahasiswa. CAkrawala Pendidikan, XXXI(3), 381-393.

Zahid, M. Z. (2020). Telaah Kerangka Kerja PISA 2021: Era Integrasi Computational Thinking dalam Bidang Matematika. PRISMA: Prosiding Seminar Nasional Matematika, 3, 706-713. 